\title{
mSOAR: an effective bedside stroke prognosis tool
}

\author{
Authors: Mark Thaller ${ }^{A}$ and Nicholas Mitchell ${ }^{B}$
}

The modified-SOAR (mSOAR) score is composed of the stroke subtype, Oxfordshire Community Stroke Project classification, age, pre-stroke modified Rankin score (mRS) and the National Institutes of Health Stroke Scale score. It has previously been shown to be a reliable predictor of mortality and length of hospital stay. This study sought to identify whether the mSOAR can also be used to predict patient disability on discharge. A post-hoc calculation of mSOAR using Sentinel Stroke National Audit Programme (SSNAP) data and electronic discharge summaries was performed on all stroke admissions to Bridgend Hospital over an 11-month period. This study included $230 \mathrm{pa}-$ tients, of which $88 \%$ had suffered infarcts and $23 \%$ had experienced a previous cerebrovascular episode or transient ischaemic attack; $52 \%$ were female. The mortality rate was $13 \%$ and $57 \%$ had slight disability or less ( $\mathrm{mRS} \leq 2)$ on discharge. Each increase in mSOAR score was associated with significantly worse discharge disability $(p<0.05)$. We conclude that the mSOAR score is an excellent tool for predicting both discharge disability and mortality. As such, it's useful for admission prognosis discussions with patients, their relatives and the multidisciplinary team and for early supported discharge decision making.

KEYWORDS: Discharge disability, mortality, mSOAR, Rankin score, stroke prognosis

\section{Introduction}

Stroke is the second most common cause of death and third most common for years of life lost (based on life expectancy) worldwide. There has been a $24.6 \%$ reduction in agestandardised death rates between 1990 and 2010 with an associated increase in disability. ${ }^{1}$ The sudden nature of stroke and its potential to impact biological, psychological and social functions with variable recovery is worrying for both patients and their families. ${ }^{2}$ Therefore, the ability to predict recovery with good accuracy enables the medical team to manage the expectations of patients and families. There are a number of prognostic tools available, but they vary in ease to obtain the required data (eg haematoma volume), the time effect on results (eg glucose) or complexity of score calculation. ${ }^{3-7}$

Authors: A core medical trainee, Princess of Wales Hospital, Bridgend, UK; ${ }^{B}$ senior house officer (locum), Princess of Wales Hospital, Bridgend, UK
However, the modified SOAR score (mSOAR) is simple to calculate with components available from initial assessment and imaging. It is composed of the National Institutes of Health Stroke Scale (NIHSS) score, stroke subtype, Oxfordshire Community Stroke Project classification, age and pre-stroke modified Rankin score (mRS) (Table 1). It has previously been derived and validated as a reliable predictor of mortality and length of stay. ${ }^{8,9}$ This study adds to current literature by assessing its ability to predict discharge disability requiring help for activities of daily living (ADLs).

\section{Methods}

A post-hoc calculation of the mSOAR score using prospectively collected Sentinel Stroke National Audit Programme (SSNAP) data and electronic discharge summaries was performed. The SSNAP data had previously been collected by the Princess of Wales Hospital, Bridgend, stroke unit team and patients had given consent for use of their anonymised data in research and reports.

The two hypotheses for this project were:

$1 \mathrm{mSOAR}$ score can predict discharge disability requiring assistance for some basic ADLs ( $\mathrm{mRS} \geq 4$ )

2 mSOAR score can predict those at increased risk of mortality (mRS 6).

The inclusion criteria were:

> patients admitted to Princess of Wales Hospital between 1 December 2014 and 31 October 2015 with a suspected stroke or event during admission

$>$ stroke data recorded in the SSNAP database

$>$ mRS recorded on admission.

The exclusion criteria were:

$>$ diagnosis on discharge not of an intracranial infarct or haemorrhage

$>$ discharge mRS not recorded.

Ethical approval was not required as this was a post-hoc analysis of existing data for which consent had been obtained as part of SSNAP.

\section{Results}

In the 11 months that this project covered, 263 patients were admitted; 20 non-stroke patients were excluded (mimics being four transient ischaemic attack, three dementia, three trauma, three seizure, three cancer, two vertigo and one 
Table 1. mSOAR calculation tool ${ }^{8,9}$

\begin{tabular}{|c|c|c|c|c|}
\hline Categories & Criteria & Description & Score & Patient's score \\
\hline \multirow[t]{2}{*}{ Stroke type } & Infarct & & 0 & \\
\hline & Haemorrhage & & 1 & \\
\hline \multirow{13}{*}{$\begin{array}{l}\text { Oxford Community Stroke } \\
\text { Project Stroke classification }\end{array}$} & Lacunar & Motor or sensory deficit only & 0 & \\
\hline & Partial anterior circulation & Two of: & 0 & \\
\hline & & motor or sensory & & \\
\hline & & higher cortical dysfunction & & \\
\hline & & hemianopia & & \\
\hline & Posterior circulation & Any of: & 1 & \\
\hline & & brainstem signs & & \\
\hline & & cerebellar signs & & \\
\hline & & isolated hemianopia & & \\
\hline & Total anterior circulation & Three of: & 2 & \\
\hline & & motor or sensory & & \\
\hline & & higher cortical dysfunction & & \\
\hline & & hemianopia & & \\
\hline \multirow[t]{3}{*}{ Age } & $\leq 65$ & & 0 & \\
\hline & $66-85$ & & 1 & \\
\hline & $\geq 86$ & & 2 & \\
\hline \multirow{6}{*}{$\begin{array}{l}\text { Modified Rankin scale (Pre- } \\
\text { stroke) }\end{array}$} & 0 & No symptoms & 0 & \\
\hline & 1 & $\begin{array}{l}\text { No significant disability. Able to carry out all } \\
\text { usual activities, despite some symptoms. }\end{array}$ & 0 & \\
\hline & 2 & $\begin{array}{l}\text { Slight disability. Able to look after own affairs } \\
\text { without assistance, but unable to carry out all } \\
\text { previous activities. }\end{array}$ & 0 & \\
\hline & 3 & $\begin{array}{l}\text { Moderate disability. Requires some help, but } \\
\text { able to walk unassisted. }\end{array}$ & 1 & \\
\hline & 4 & $\begin{array}{l}\text { Moderately severe disability. Unable to attend } \\
\text { to own bodily needs without assistance, and/or } \\
\text { unable to walk unassisted. }\end{array}$ & 1 & \\
\hline & 5 & $\begin{array}{l}\text { Severe disability. Requires constant nursing care } \\
\text { and attention, bedridden, incontinent. }\end{array}$ & 2 & \\
\hline \multirow{4}{*}{$\begin{array}{l}\text { Admission National } \\
\text { Institutes of Health Stroke } \\
\text { Scale score }\end{array}$} & $0-4$ & & 0 & \\
\hline & $5-10$ & & 1 & \\
\hline & $\geq 11$ & & 2 & \\
\hline & & TOTAL SCORE & & \\
\hline
\end{tabular}

cardiac diagnoses) and 14 had incomplete discharge data. Of the 230 patients included in this study, 203 (88\%) had had infarctions, 119 (52\%) were female, 180 (78\%) were aged 70 years or over and $53(23 \%)$ had had a previous cerebrovascular episode or transient ischaemic attack. Of the 203 patients who had suffered infarcts, 43 (21\%) had known atrial fibrillation with 17 patients on anticoagulation preadmission. Hypertension was prevalent, with 120 patients with infarct and 14 of the patients with intracranial bleeds having a past medical history of it. On discharge, 130 (57\%) patients had only slight disability or less (mRS $\leq 2)$ and 31 patients $(13 \%)$ died during admission.

Each increase in mSOAR score was associated with statistically significant $(\mathrm{p}<0.05)$ worsening of discharge disability (Fig 1), up to a score of 5 . There is also a statistically significant $(\mathrm{p}<0.001)$ worse discharge disability associated 


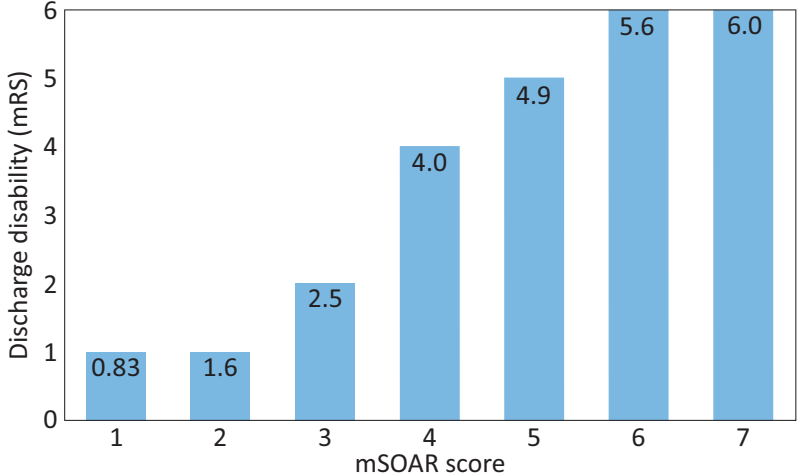

Fig 1. mSoar versus median discharge disability (mean values given). $\mathrm{mRS}$ = modified Rankin score; $\mathrm{mSOAR}$ = modified stroke subtype, Oxfordshire Community Stroke Project classification, age, pre-stroke modified Rankin score and the National Institutes of Health Stroke Scale score

with $\mathrm{mSOAR} \geq 4$ (Fig 2), with $81 \%$ of those patients who died being in this category. When comparing MSOAR with change in $\mathrm{mRS}$, thus skewing results away from those with high prestroke dependency, the results were still significant (mSOAR 1-2 versus 3-4 corresponded to an mRS of 0.9 versus 2.0 , respectively $(\mathrm{p}<0.001)$ and $\mathrm{mSOAR} 3-4$ versus $5-8$ with an mRS of 2.0 versus $3.4, p=0.001$ ).

The mSOAR is an excellent predictor of moderate to severe disability (area under the receiver operating characteristic curve (auROC) 0.86 (95\% CI 0.81-0.90)) and inpatient mortality (0.97 (95\% CI 0.94-0.99)) (Table 2).
As we expected, the length of stay was longer in those patients with higher discharge disabilities who survived (median 58 days, (interquartile range (IQR) 37-71 days) for mRS 4-5 versus 11 days (IQR 6-20 days) for $m R S 0-3, p<0.001$ ) but shorter in those who died (13 days (IQR 7-25 days), $\mathrm{p}<0.001$ ). Similarly, higher mSOAR scores were associated with longer median length of stay for those that survived to discharge $(\mathrm{p}<0.001)$. This corresponded with higher disability, but was not significant $(\mathrm{p}>0.05)$ for inpatient mortality. This is likely due to small numbers with low scores.

\section{Discussion}

This study has shown that in our population of patients admitted to Princess of Wales Hospital, Bridgend, the mSOAR score is an excellent predictor of moderate-severe disability (mRS $\geq 4)$ and mortality as shown from ROC curve results. Therefore, its use as part of acute stroke admission would enable more informed admission prognostic discussions and earlier multidisciplinary discharge planning meetings. Accelerating discharge planning could aid time efficient transfer of patients to appropriate locations, eg to a rehabilitation unit or to home with early supported discharge team input. Not only will this be of benefit to those affected but also to patient flow, thus enabling more appropriate and effective use of inpatient stroke service resources. However, we recognise that for time efficient transfer of patients there needs to be an increase in community resources as well as a cultural change away from delaying the discharge process until patients are 'medically stable for discharge'.

Our results show that recovery to discharge with moderatesevere disability (mRS 4-5) takes significantly longer than those

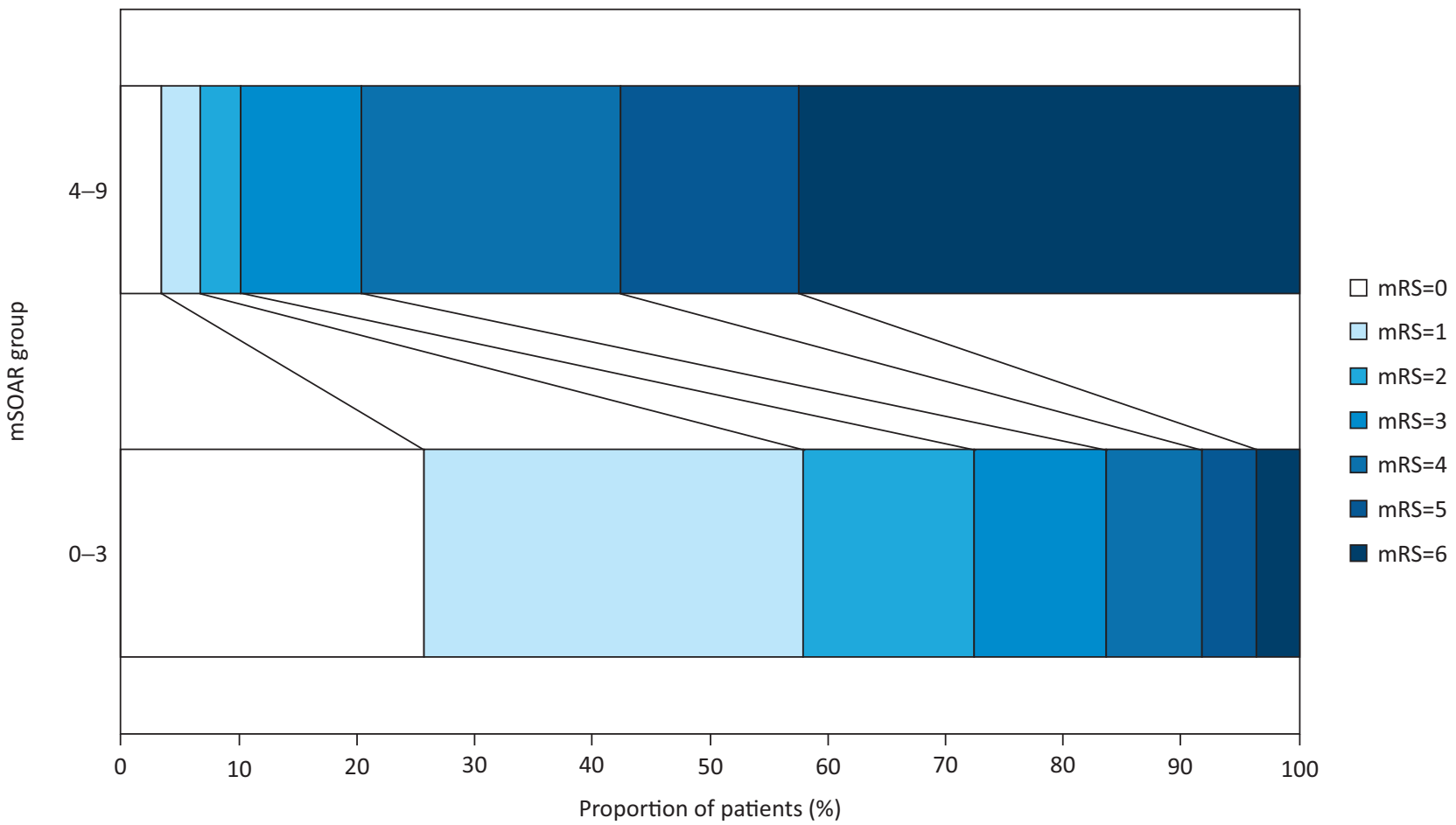

Fig 2. Comparison of discharge disability (mRS) by mSOAR grouping. mRS = modified Rankin score; mSOAR = modified stroke subtype, Oxfordshire Community Stroke Project classification, age, pre-stroke modified Rankin score and the National Institutes of Health Stroke Scale score 
Table 2. Prediction of discharge disability (moderate-severe disability $(m R S \geq 4))$ and mortality $(m R S=6)$

\begin{tabular}{|c|c|c|c|c|c|}
\hline mSOAR cut off point & $\mathrm{n}$ & Sensitivity (95\% CI) & Specificity (95\% CI) & PPV & NPV \\
\hline \multicolumn{6}{|l|}{$\mathrm{mRS} \geq 4$} \\
\hline$\geq 2$ & 188 & $100(95.2-100.0)$ & $27.1(20.3-34.8)$ & 39.9 & 100 \\
\hline$\geq 3$ & 116 & $84(73.7-91.4)$ & $65.81(57.8-73.2)$ & 54.3 & 89.5 \\
\hline$\geq 4$ & 59 & $62.67(50.7-73.6)$ & $92.26(86.9-95.9)$ & 79.7 & 83.6 \\
\hline$\geq 5$ & 29 & $37.33(26.4-49.3)$ & 99.35 (96.5-100.0) & 96.6 & 76.6 \\
\hline$\geq 6$ & 13 & $17.33(9.6-27.8)$ & $100(97.6-100.0)$ & 100 & 71.4 \\
\hline$\geq 7$ & 5 & $6.67(2.2-14.9)$ & $100(97.6-100.0)$ & 100 & 68.9 \\
\hline$\geq 8$ & 1 & $1.33(0.03-7.2)$ & $100(97.6-100.0)$ & 100 & 67.7 \\
\hline \multicolumn{6}{|l|}{$\mathrm{mRS}=6$} \\
\hline$\geq 2$ & 188 & $100(88.8-100.0)$ & $21.1(15.7-27.4)$ & 16.5 & 100 \\
\hline$\geq 3$ & 116 & $93.6(78.6-99.2)$ & $56.3(49.1-63.3)$ & 25 & 98.2 \\
\hline$\geq 4$ & 59 & $80.7(62.5-92.5)$ & $82.9(77.0-87.9)$ & 42.4 & 96.5 \\
\hline$\geq 5$ & 29 & $54.8(36.0-72.7)$ & 93.9 (89.7-96.8) & 58.6 & 93 \\
\hline$\geq 6$ & 13 & $32.3(16.7-51.4)$ & 98.5 (95.7-99.7) & 76.9 & 90.3 \\
\hline$\geq 7$ & 5 & $12.9(3.6-29.8)$ & $99.5(97.2-100.0)$ & 80 & 88 \\
\hline$\geq 8$ & 1 & $0(0.0-11.2)$ & 99.5 (97.2-100.0) & 0 & 86.5 \\
\hline
\end{tabular}

mRS = modified Rankin score; mSOAR = modified stroke subtype, Oxfordshire Community Stroke Project classification, age, pre-stroke modified Rankin score and the National Institutes of Health Stroke Scale score; NPV = negative predictive value; PPV = positive predictive value

with mild-moderate disability (mRS 0-3). As such, the mSOAR criteria could enable earlier prediction of discharge disability. This in turn can enable initiation of the discharge process earlier with the potential to dramatically shorten number of days in the acute stroke unit. There are a multitude of benefits to this, including earlier rehabilitation in the community and reduced hospital-acquired infections.

The mSOAR could miss some patients who may deteriorate unexpectedly following admission (eg haemorrhagic transformation or secondary pneumonia) $)^{10}$ as well as others improving despite severe infarct or haemorrhage. Therefore, we would advise that no prognostic tool should be used as the sole basis of management decisions.

The components of the mSOAR have been widely shown to be predictors of outcome. They are stroke type, anatomical location (Oxford Community Stroke Project classification), age, pre-stroke disability (mRS) and stroke severity (NIHSS) ${ }^{11-19}$ In addition to combining these elements, it has also been validated in both ischaemic and haemorrhagic strokes, unlike other current prognostic tools, thus making it easier to integrate into clinical practice.

One perceived limitation of the mSOAR scoring system in this study is that we have used the mRS score as a marker of disability despite it being a component of the mSOAR scoring system. The mRS score is an indicator of a person's level of dependence, a marker of frailty. It has previously been shown to be a predictor of patient outcomes, including mortality. ${ }^{8,20}$ Therefore, it follows that a patient admitted dependent for all ADLs is not going to be discharged independent and is closer to the mortality end of the outcome spectrum. Our results are significant when comparing mSOAR to change in $\mathrm{mRS}$. A healthy, symptom-free person who dies would have an $\mathrm{mRS}$ change of 6 and a fully dependent person who dies a change of only 1 . We conclude that the pre-stroke mRS is of value in predicting post-stroke disability but cannot independently account for why we have found the mSOAR score to be such an effective predictor of discharge disability; rather, this is likely to be due to the combination of components.

Interestingly, $5 \%$ of our study population had better discharge disability than pre-stroke disability. This may be attributable to patients with minor strokes having other problems limiting independence that were addressed effectively during their time on the stroke ward.

Limitations of this project are that there were no patients with either a minimum mSOAR score of 0 or the maximum of 9 , most likely because the former's mild symptoms and preadmission mortality for the latter. The disability on discharge was not assessed as to its correlation with place of discharge because of multifactorial reasons for the latter, such as family social support. Although this was a single-centre study, our results are in keeping with previous SOAR and mSOAR research that was assessed in over 14,000 patients. They showed an auROC of $0.79(0.78-0.80)^{8}$ and auROC 0.83 $(0.79-0.86),{ }^{9}$ respectively, for inpatient mortality prediction; therefore, they have good accuracy. We would recommend further research into mSOAR score's ability to predict other post-stroke outcomes such as cognition, mood and communication as then the appropriate therapy could be better targeted in the hyperacute and acute settings. Our findings should also be replicated in different ethnic populations and independent datasets.

\section{Conclusions}

The mSOAR score is an excellent and accurate tool for predicting discharge disability requiring additional support 
and mortality. It is useful for admission prognosis discussions with patients and their relatives. Furthermore, it can aid the multidisciplinary team in decision making for early supported discharge or to alternative appropriate destinations.

\section{Conflicts of interest}

The authors have no conflicts of interest to declare.

\section{Author Contributions}

Dr Mark Thaller - project concept, design, data collection, analysis and writing up the report.

Dr Nicholas Mitchell - data interpretation, review of literature and writing up the report.

\section{Acknowledgements}

We would like to thank our consultants Dr Diptarup Mukhopadhyay (data sign off lead for SSNAP at the Princess of Wales Hospital) and Dr Harish Bhat for their advice during this project and the dedicated multidisciplinary stroke team on ward 2 of the Princess of Wales Hospital Bridgend. We are very grateful to the patients and families who enquired about the prognosis on admission, from which this study developed to help answer those sometimes difficult questions.

\section{References}

1 Lozano R, Naghavi M, Foreman K et al. Global and regional mortality from 235 causes of death for 20 age groups in 1990 and 2010: a systematic analysis for the Global Burden of Disease Study 2010. Lancet 2012;380:2095-128.

2 Nichols-Larsen DS, Clark PC, Zeringue A, Greenspan A, Blanton S. Factors influencing stroke survivors' quality of life during subacute recovery. Stroke 2005;36:1480-4.

3 Saposnik G, Raptis S, Kapral MK et al. The iScore predicts poor functional outcomes early after hospitalization for acute ischaemic stroke. Stroke 2011;42:3421-8.

4 Smith EE, Shobha N, Dai D et al. Risk score for in-hospital ischaemic stroke mortality derivated and validated within the Get With the Guidelines-Stroke Program. Circulation 2010;122:1496-504.

5 Wang Y, Lim LLY, Levi C et al. A prognostic index for 30-day mortality after stroke. J Clin Epidemiol 2001;54:766-73.

6 Papavasileiou V, Milionis H, Michel P et al. ASTRAL score predicts 5 -year dependence and mortality in acute ischaemic stroke. Stroke 2013;44:1616-20.

7 Counsell C, Dennis M, McDowall M, Warlow C. Predicting outcome after acute and subacute stroke development and validation of new prognostic models. Stroke 2002;33:1041-7.

8 Myint PK, Clark AB, Kwok CS et al. The SOAR (Stroke subtype, Oxford Community Stroke Project classification, Age, prestroke modified Rankin) score strongly predicts early outcomes in acute stroke. Int J Stroke 2014;9:278-83.
9 Abdul-Rahim AH, Quinn TJ, Alder S et al. Derivation and validation of a novel prognostic scale (modified-stroke subtype, Oxfordshire Community Stroke Project classification, age, and prestroke modified Rankin) to predict early mortality in acute stroke. Stroke 2016;47:74-9.

10 Koennecke HC, Belz W, Berfelde D et al. Factors influencing inhospital mortality and morbidity in patients treated on a stroke unit. Neurology 2011;77:965-72.

11 Jr Adams HP, Davis PH, Leira EC et al. Baseline NIH Stroke Scale score strongly predicts outcome after stroke: a report of the Trial of Org 10172 in Acute Stroke Treatment (TOAST). Neurology 1999;53:126-31.

12 Andersen KK, Andersen ZJ, Olsen TS. Predictors of early and late case-fatality in a nationwide Danish study of 26,818 patients with first-ever ischemic stroke. Stroke 2011;42:2806-12.

13 Béjot $\mathrm{Y}$, Troisgros $\mathrm{O}$, Gremeaux V et al. Poststroke disposition and associated factors in a population-based study: the Dijon Stroke Registry. Stroke 2012;43:2071-7.

14 Di Carlo A, Lamassa M, Baldereschi $M$ et al. Risk factors and outcome of subtypes of ischemic stroke. Data from a multicenter multinational hospital-based registry. The European Community Stroke Project. J Neurol Sci 2006;244:143-50.

15 Kammersgaard LP, Jørgensen HS, Reith J et al. Short- and longterm prognosis for very old stroke patients. The Copenhagen Stroke Study. Age Ageing 2004;33:149-54.

16 Kelly-Hayes M, Beiser A, Kase CS et al. The influence of gender and age on disability following ischemic stroke: the Framingham study. J Stroke Cerebrovasc Dis 2003;12:119-26.

17 Muir KW, Weir CJ, Murray GD, Povey C, Lees KR. Comparison of neurological scales and scoring systems for acute stroke prognosis. Stroke 1996;27:1817-20.

18 Nedeltchev K, der Maur TA, Georgiadis D et al. Ischaemic stroke in young adults: predictors of outcome and recurrence. J Neurol Neurosurg Psychiatry 2005;76:191-5.

19 Weimar C, König IR, Kraywinkel K et al. Age and National Institutes of Health Stroke Scale Score within 6 hours after onset are accurate predictors of outcome after cerebral ischemia: development and external validation of prognostic models. Stroke 2004;35:158-62.

20 Kwok CS, Clark A, Ford GA et al. Association between prestroke disability and inpatient mortality and length of acute hospital stay after acute stroke. J Am Geriatr Soc 2012;60:726-32.

Address for correspondence: Dr Mark Thaller, Neurology department, Gowers Ward, Morriston Hospital, Swansea, SA6 6NL.

Email: mark.thaller@doctors.org.uk 